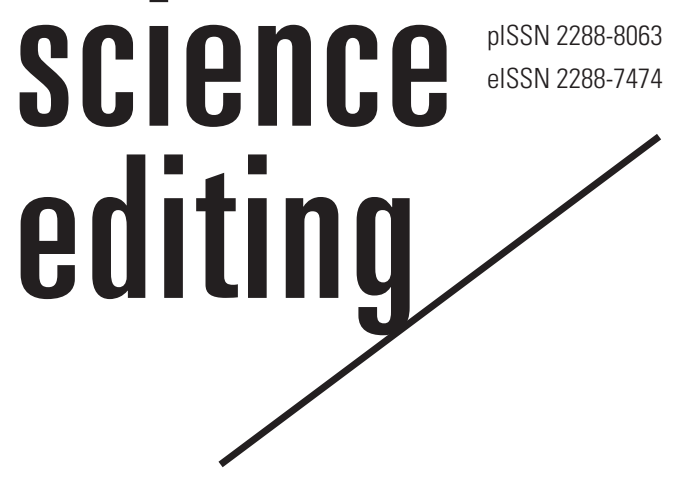

\title{
Citation performance of Indonesian scholarly journals indexed in Scopus from Scopus and Google Scholar
}

\author{
Lukman Lukman', Yan Rianto', Shidiq Al Hakim', Irene M Nadhiroh², \\ Deden Sumirat Hidayat ${ }^{3}$
}

${ }^{1}$ Research Center for Informatics, Indonesian Institute of Science, Cibinong; ${ }^{2}$ Research Center for Science and Technology Development Studies, Indonesian Institute of Science, Jakarta; ${ }^{3}$ Research Center for Biology, Indonesian Institute of Science, Cibinong, Indonesia

\begin{abstract}
Citation frequency is an important factor for estimating the quality of a scientific journal, and the number of citations that an academic paper receives is often used as a measure of its scientific impact. This study aimed to characterize the citation performance of scientific journals published by Indonesian publishers that have been indexed in Scopus by analyzing the number of citations available in the Scopus database and Google Scholar. The results of the study identified 30 Indonesian journals that have been Scopus-indexed, of which 22 were listed in SCImago Journal Rank up to October 2017. Journals in the engineering field were the most cited, with 2,427 citations, including 930 self-citations. A large proportion of the citations were of recently-founded journals. The mean proportional difference in the citation frequency between Scopus and Google Scholar was 14.71\%.
\end{abstract}

Keywords

Citation analysis; Google Scholar; Scholarly journal performance; Scopus

Received: November 14, 2017

Accepted: January 9, 2018

Correspondence to Lukman Lukman lukm006@lipi.go.id

ORCID

Lukman Lukman

http://orcid.org/0000-0001-9633-6964

Yan Rianto

http://orcid.org/0000-0001-6056-6741

Shidiq Al Hakim

http://orcid.org/0000-0002-4677-3661

Irene M Nadhiroh

http://orcid.org/0000-0002-1417-6117

Deden Sumirat Hidayat

http://orcid.org/0000-0002-1847-8665

\section{Introduction}

Scopus is a multidisciplinary database, with 67 million records (as of August 2017) and more than 22,794 peer-reviewed journal titles in the life sciences, social sciences, health sciences, and physical sciences. Records in the database start from 1,823, and references are listed starting in 1996 [1]. Google Scholar is a search engine that searches the scholarly literature, including journal articles, proceedings, theses, dissertations, books, book chapters, reports, manuscripts, newsletters, encyclopedia entries, government documents, and patents. Citations are identified through intellectual impact, and primarily comprise citations from journal articles, which account for almost $92 \%$ of citations on Google Scholar [2]. 


\section{science editing /}

We aimed to characterize the journal metrics of Indonesian journals indexed in Scopus, and in particular, to analyze the frequency of citations from Scopus and Google Scholar.

We hypothesized that Indonesian journals listed in Scopus would show a higher frequency of citations from Google Scholar than from Scopus. The results of this analysis will provide insights into the citation frequencies of Indonesian scholarly journals indexed in Scopus not only from Scopus, but also from Google Scholar.

\section{Study Design}

This was a descriptive study based on the analysis of a literature database.

\section{Definition of Terminology}

Scholarly journals refer to periodicals that publish research articles, are concerned with serious studies within a particular discipline, and follow an acceptable form of academic inquiry. Indonesian journals were defined as journals that indicated Indonesia as the country or territory of the publication.

\section{Data Sources}

Data for this study were obtained from 3 main sources: Scopus (https://www.scopus.com/sources.uri), which contains the master list of Indonesian journals indexed in Scopus; the SCImago Journal and Country Rank (http://www.scimagojr. com/index.php) powered by Scopus, which contains international scholarly publications and citations from Scopus between 2013 and 2016; and Google Scholar (https://scholar. google.co.id/)

Data collection was carried out from August 6 to 8, 2017. Thirty Indonesian scholarly journals indexed in Scopus were

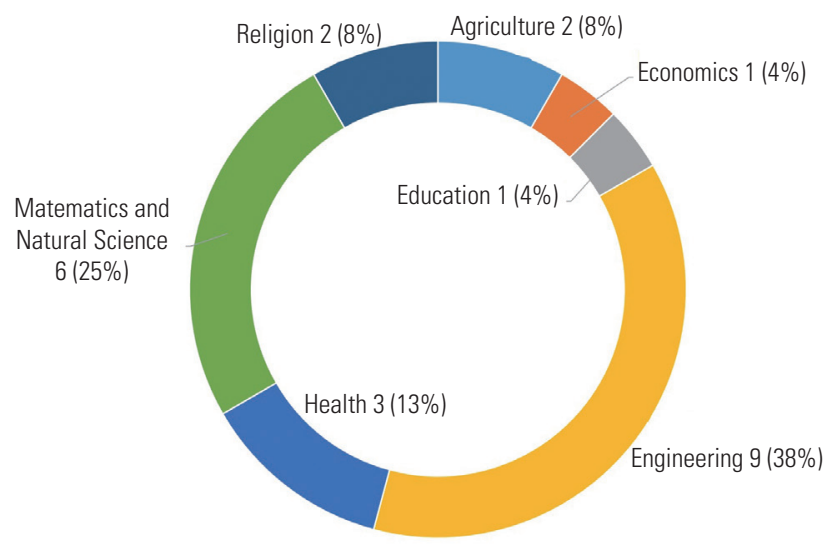

Fig. 1. Classification of Scopus-indexed journals into 7 fields. identified, of which 22 were available in SCImago Journal Rank.

\section{Analysis}

Subjected scholarly journals were classified according to research field. Furthermore, those were divided according to age of journal. After that, we compared the citation frequency of the journals published from 2013 to 2016, from Scopus and Google Scholar. The regression analysis between citation frequency from Scopus and that from Google Scholar was done.

\section{Indonesian Journals Cited in Scopus}

An analysis of journals according to field and age was conducted to understand trends in terms of which Indonesian scholarly journals were indexed and cited by Scopus. Figure 1 shows a classification of Scopus-indexed journals into 7 fields; most belonged to the field of engineering studies (38\%). The number of citations from Scopus journals from 2013 to 2016 is shown in Fig. 2. The engineering field was the most cited, with 2,427 citations and 930 self-citations.

Indonesian scholarly journals were divided into 3 categories by age: 1 to 20,21 to 40 , and 41 to 60 years (Fig. 3). The largest number of journals was found in the group aged 1 to 20 years (54\%); while the fewest journals were included in the group aged 21 to 40 years (21\%). Figure 4 shows that recentlyfounded journals received the most citations. The citation and self-citation rates from 2013 to 2016 are shown in Fig. 5.

\section{Comparison of the Citations of Indonesian Journals in Scopus and Google Scholar}

Fig. 6 presents a comparison of the citations of Indonesian scholarly journals in Scopus versus Google Scholar from 2013 to 2016. Table 1 contains a detailed comparison of the cita-

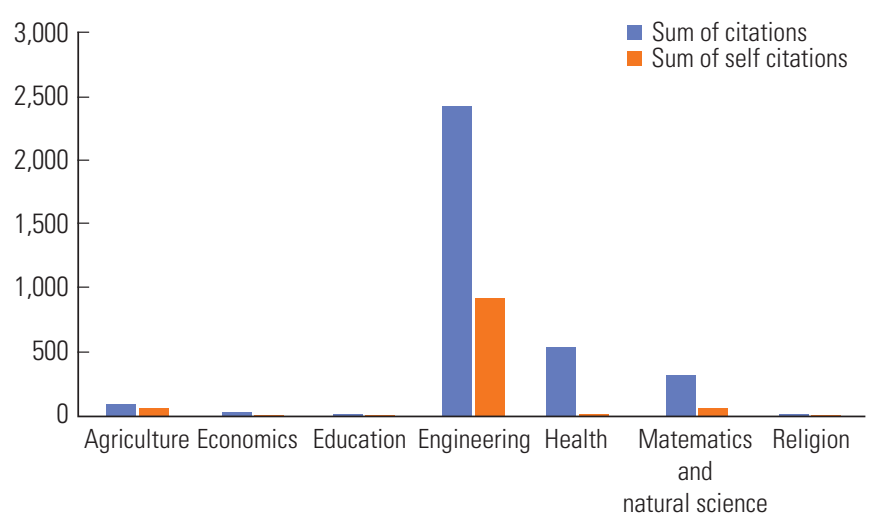

Fig. 2. Number of citations from Scopus journals from 2013 to 2016. 


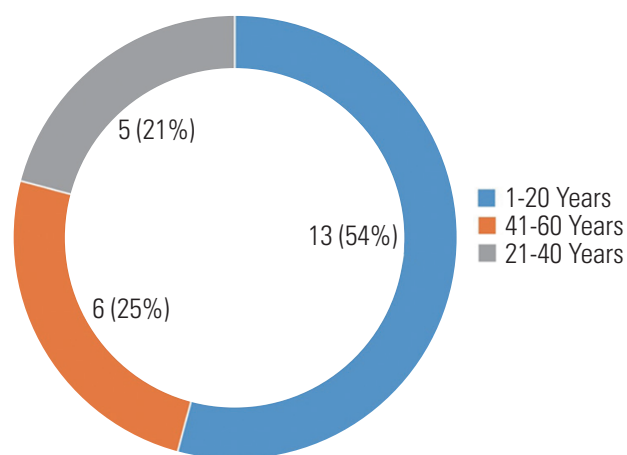

Fig. 3. Classification of journals by age.

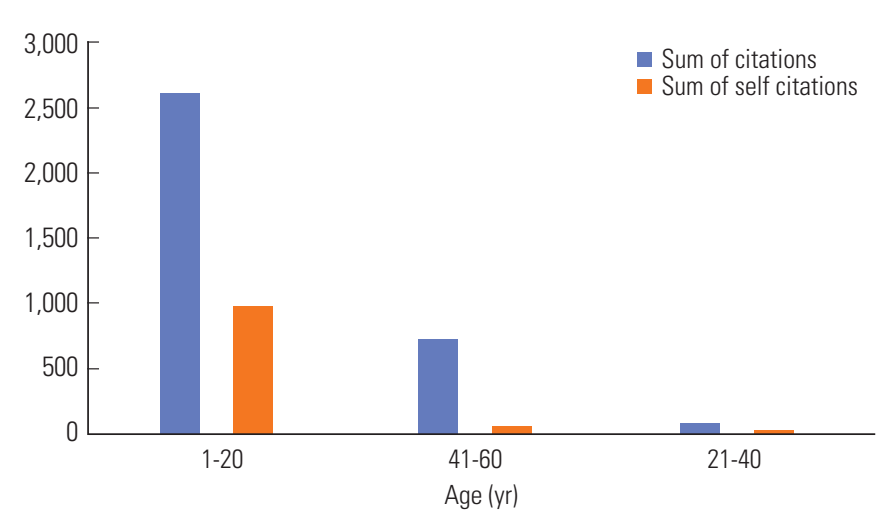

Fig. 4. Citations divided by the age group of journals.

tions of Indonesian scholarly journals in Scopus and Google Scholar from 2013 to 2016.

\section{Differences, Correlations, and Regression Analysis of Citations from Scopus and Google Scholar}

The mean number of Scopus citations was 134.38, while the mean for Google Scholar citations was 719 (Suppl. 1). The variance of both citations was quite high. Pearson correlation analysis was used to measure the linear relationship between Scopus citations and Google Scholar citations. The Pearson correlation coefficient was 0.79 , indicating a strong relationship between the Scopus and Google Scholar citations. The ttest for paired observations was used to evaluate the statistical difference between Google Scholar citations and Scopus citations. The hypothesis for the t-test was:

H0: The mean difference between Google Scholar citations and Scopus citations was equal to zero.

H1: The mean difference between Google Scholar citations and Scopus citations was not equal to zero.

The t-test resulted in a 2-tailed P-value of 0.0000847 (Suppl. 1). This result indicates that $\mathrm{H} 0$ was rejected, meaning that

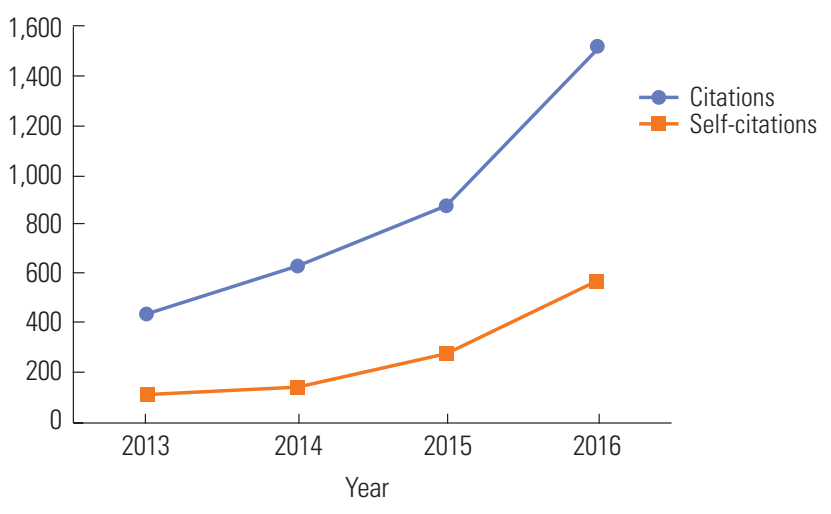

Fig. 5. Citations and self-citations versus year.

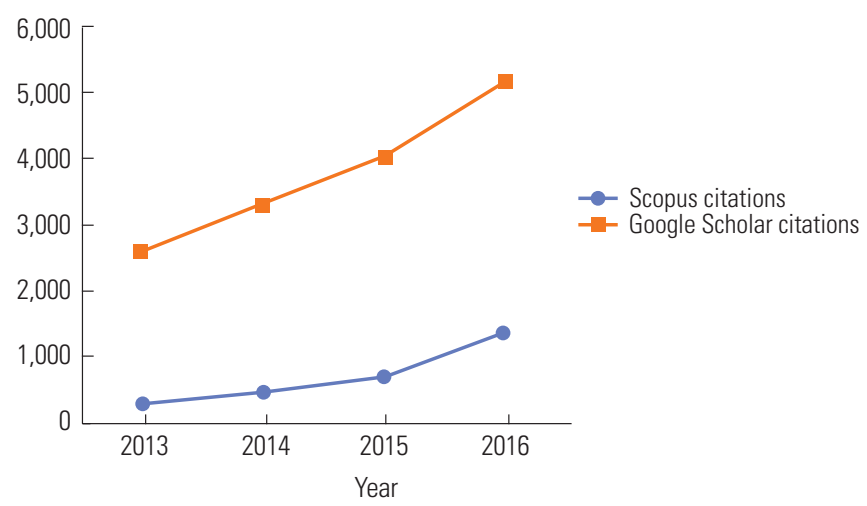

Fig. 6. Scopus citations and Google Scholar citations versus year.

there was a significant difference between the mean number of Scopus citations and Google Scholar citations of Indonesian journals indexed by Scopus.

Figure 7 presents a scatter plot of Google Scholar citations and Scopus citations, showing a linear relationship. The adjusted R-squared was 0.60 (Suppl. 2). This result is quite good, and indicates that $60 \%$ of the variance that appeared in the Scopus citations was explained by the Google Scholar citations. The t-test for the regression analysis also showed that the regression coefficient was statistically significant, with a Pvalue of less than $5 \%$ of alpha. Given the strong statistical correlation of citations at the article level in Google Scholar and Scopus, the 2 databases are to some extent interchangeable for bibliometric analyses. The regression analysis also showed a strong statistical correlation at the journal level.

\section{Policy of Indonesian Government to Support Scholarly Work}

The government of Indonesia has supported the development of world-class universities and research institutions that focus on research, innovations, and publications. Given this focus, 
Table 1. Comparison of citations to Indonesia scholarly journals indexed in Scopus from Scopus and Google Scholar

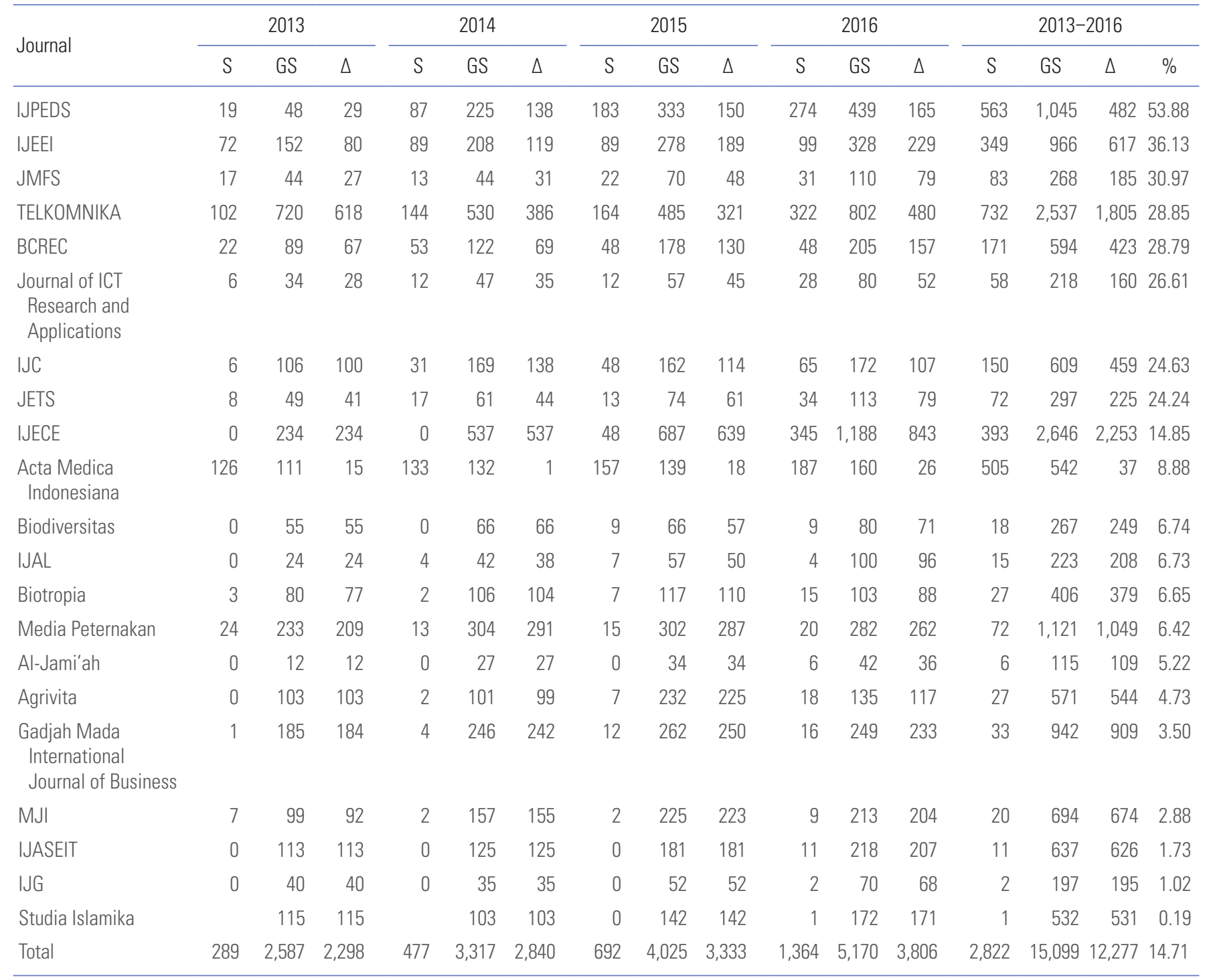

S, Scopus Citation; GS, Google Scholar Citation; $\triangle$, difference Scopus and Google Scholar citation; IJPEDS, International Journal of Power Electronics and Drive Systems; IJEEI, International Journal of Electrical Engineering and Informatics; JMFS, Journal of Mathematical and Fundamental Sciences; BCREC, Bulletin of Chemical Reaction Engineering \& Catalysis; IJC, Indonesian Journal of Chemistry; JETS, Journal of Engineering and Technological Sciences; IJECE, International Journal of Electrical and Computer Engineering; IJAL, Indonesian Journal of Applied Linguistics; MJI, Medical Journal of Indonesia; IJASEIT, International Journal on Advanced Science, Engineering and Information Technology; IJG, Indonesian Journal of Geography.

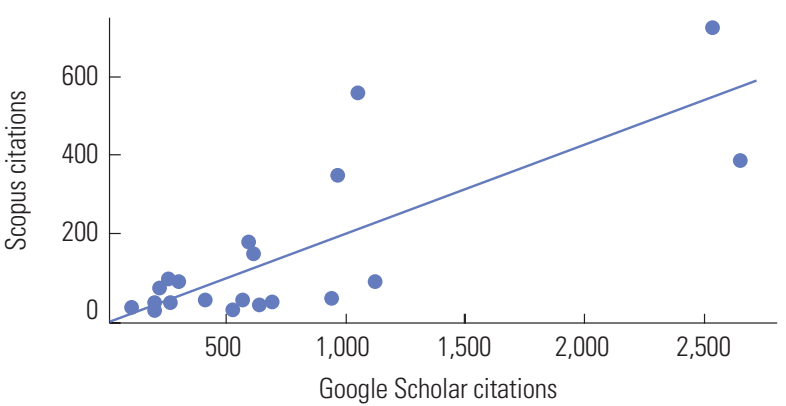

Fig. 7. Scopus citations versus Google Scholar citations. publications and citations can influence decisions regarding research contracts and remuneration for academics and research group members. It is important to conduct a brief assessment of the yearly citation and publication performance of scientific journals. This policy has been endorsed by the Indonesian Ministry of Research and Higher Education by providing funding and incentives for journals indexed in Scopus with high citation rates, especially from SCImago Journal Rank and Google Scholar, because high citation frequencies indicate that the quality and visibility of a journal justify the 
investment of resources.

\section{Competency of Indonesian Scholarly Journals According to Citation}

In this context, how Indonesian journals fare in terms of receiving citations in international citation databases has not yet been studied. In this paper, we analyzed the citation results of Indonesian journals listed in Scopus in Scopus and Google Scholar. Citation frequency may reflect a journal's value, authority, and use.

The self-citation rate of Indonesian journals indexed in Scopus from 2013 to 2016 ranged from 0\% to 100\%. An important consideration when evaluating self-citations that should be taken into account is the diversity of research output across disciplines. The social sciences and the arts and humanities produce and communicate knowledge differently from the natural sciences, engineering, computer science, and medicine.

\section{Limitation}

Citations in Google Scholar have certain flaws; among others, the Google Scholar effect is a phenomenon in which some researchers cite works that appear in the top results in Google Scholar, regardless of their contribution to the publication, because they automatically assume that such articles are credible and believe that editors, reviewers, and readers will expect to see that citation [3]. Google Scholar still has limitations in detecting areas of interest and incorrect research, as well as problems correctly identifying publications on the arXiv initial print server. The inclusion of characters between characters in the title resulted in incorrect search results, and inputting the authors of the wrong paper led to additional wrong search results. Some search results are even given for no understandable reason [4].

Google Scholar is vulnerable to spam [5]. Researchers from the University of California, Berkeley and Otto-von-Guericke University Magdeburg pointed out that the number of citations in Google Scholar can be manipulated and that nonsensical papers made with SCIgen were indexed in Google Scholar [6]. They concluded that Google Scholar should be used with caution, especially for calculating performance metrics such as the h-index or impact factor. Google Scholar started calculating the h-index in 2012, with the appearance of individual Google Scholar profile pages. The practicality of manipulating the $\mathrm{H}$-index calculator in Google Scholar was shown in 2010 by Cyril Labbe of Joseph Fourier University, who successfully ranked "Ike Antkare" above Albert Einstein using a set of SCIgen-made documents citing each other (effectively an academic link farm) [7].
The last limitation of Google Scholar is the lack of filtering to improve quality. Google Scholar indexes as many journals as possible, including predatory journals that will contaminate the global scientific record. This means that information found on Google Scholar should be confirmed elsewhere. In the field of citation counting, Google Scholar proved to be easily manipulated, and included a number of duplicate citations.

\section{Conclusion}

The analyses presented in Table 1 and Fig. 6 showed that the mean proportional difference in citation frequency between Scopus and Google Scholar was $14.71 \%$. Based on these data, it can be concluded that the hypothesis that Google Scholar citations would be more common than Scopus citations was proven. The citations in Scopus were mostly from Scopus-indexed publications, whereas the Google Scholar citations were a more diverse range of publications available online. Google Scholar has a scope and excellence of citations comparable to controlled databases such as Scopus, which is highly selective, has an English-language bias, and uses journals as the document source. Google Scholar also demonstrates the power of citation metrics that track all disciplines because of the inclusion of non-English, free, and open-access resources. Furthermore, scatter plot of Google Scholar citations and Scopus citations, showed a linear relationship (the adjusted R2 0.60) between two kinds of citations.

\section{Conflict of Interest}

No potential conflict of interest relevant to this article was reported.

\section{Acknowledgments}

We acknowledge the Indonesian Institute of Sciences and funding received from Insentif Sistem Inovasi Nasional (Insinas) Programme of the Ministry of Research, Technology, and Higher Education (grant no. 062/P/RPL-LIPI/INSINAS-2/VI/2017).

\section{Supplementary Material}

Supplementary file is available from: https://doi.org/10.6087/ kcse.119

Suppl. 1. t-test for the paired mean difference of citations from Scopus and Google Scholar

Suppl. 2. Results of the regression analysis between citation frequency from Scopus and that from Google Scholar 


\section{References}

1. Elsevier. Scopus content at-a-glance [Internet]. Amsterdam: Elsevier; 2017 [cited 2017 Aug 8]. Available from: https://www.elsevier.com/solutions/scopus/content

2. Harzing AW, van der Wal R. Google Scholar as a new source for citation analysis. Ethics Sci Environ Polit 2008; 8:61-73. https://doi.org/10.3354/esep00076

3. Serenko A, Dumay J. Citation classics published in Knowledge Management journals. Part II: studying research trends and discovering the Google Scholar Effect. J Knowl Manag 2015;19:1335-55. https://doi.org/10.1108/JKM-022015-0086

4. Jasco P. Google Scholar's ghost authors, lost authors, and other problems: why the popular tool can't be used to analyze the publishing performance and impact of researchers. Libr J 2009;9:2009.

5. Beel J, Gipp B. On the robustness of Google Scholar against spam. Paper presented at: the 21st ACM Conference on Hypertext and Hypermedia; 2010 Jun 13-16; Toronto, $\mathrm{ON}$, Canada.

6. Gipp JB, Beel J, Gipp B. Academic search engine spam and Google Scholar's resilience against it. J Electron Publ 2010;13. https://doi.org/10.3998/3336451.0013.305

7. Labbe C. Ike Antkare one of the great stars in the scientific firmament [dissertation]. Saint-Martin-d'Heres: Universite Joseph Fourier; 2010. 